\title{
Children's Outdoor Activities and Parenting Style in Children's Social Skill
}

\author{
Chandrawaty ${ }^{1}$ \\ University of Muhammadiyah Prof. DR. HAMKA \\ Susianty Selaras Ndari ${ }^{2}$ \\ University of Muhammadiyah Prof. DR. HAMKA \\ Imam Mujtaba ${ }^{3}$ \\ Universitas Muhammadiyah Jakarta \\ Mafaza Conita Ananto ${ }^{4}$ \\ Universitas Muhammadiyah Prof. DR. HAMKA
}

DOI: https://doi.org/10.21009/JPUD.132.02

Accepted: August $15^{\text {th }} 2019$. Approved: September $4^{\text {th }} 2019$. Published: $30^{\text {th }}$ November 2019

\begin{abstract}
Physical activity is very important for early childhood, especially outdoor activities that add a lot of new experiences. This study aims to check the relationship of children's outdoor activities and parenting styles and children's social skills. The participants are 125 parents of early childhood who attend kindergarten. The research method is a descriptive study using the relational screening model. The results showed that there was a relationship between outside play and parenting style on the social skills of children in their childhood. Democratic parenting styles are found to promote children's social skills, while authoritative parenting styles have a negative correlation with interpersonal skills, the ability to express verbally, self-control, listening skills, emotional management and adaptation to change. In the sub-dimensions of anger management and adaptation to changing skills is a significant difference between authoritative parenting styles and not permissive parenting with children's social skills.
\end{abstract}

Keywords: Early Childhood Social skills, Outdoor Activities, Parenting Styles

(C) 2019 Early Childhood Education Post Graduate Program UNJ, Jakarta

e-ISSN (Online Media): 2503-0566

P-ISSN (Print Media): 1693-1602

\footnotetext{
${ }^{1}$ Corresponding Author:

Chandrawaty

Email: chandrawaty.dikdas@yahoo.com

${ }^{2}$ Email: susilaras@uhamka.ac.id

${ }^{3}$ Email: imam.mujtaba@umi.ac.id
} 


\section{INTRODUCTION}

Urban residential problems had a negative impact for the lives of children, especially with the limited outdoor space. In expanse competition, developers tend to build land for high building use and investment property for the sake of trade benefits (Shi, 2017). Azlina \& S., (2012) have stated their lack of a natural environment for children's outdoor playgrounds is very clear in urban residential areas. children's outside playroom to have deficiencies in cause of supporting condition, kinds and playable-functional areas and they are integrated with adult fitness facilities and some community activities. Parks and play areas in the city fall apart and centers for leisure activities are not widely available. The condition of the city led to the emergence of family violence, child abuse and neglect, adolescent antisocial activities, and juvenile delinquency behavior (Zajenkowska, Jankowski, Lawrence, \& Zajenkowski, 2013). Accordingly, there is a little opportunity for children to attend outdoor activities due to limited area provided by the developers.

Methods In the capital of Jakarta, limited public space for children has also been problems as many places in Jakarta is surrounded by multi-store buildings, leaving only a narrow open space for children to play directly with natural objects. Early childhood children under 8 years old commonly enjoy playing outside by exploring the environment together with their peers. They do this to live through all aspects of their development. Playing outdoors willingly, and without restriction is very important for the physical activities and their developments (Junot, Paquet, \& Martin-Krumm, 2017). Three girls and boys say they like to plant seeds. Most children claim that they always play with animals in the environment around their place of residence (GhanbariAzarneir, Anbari, Hosseini, \& Yazdanfar, 2015).

The children are able to develop physical, mental and creative abilities by playing outside (Kozina et al., 2016). In addition, outdoor learning is believed to promote motivation, and academic achievement, increasing self-confidence and social development, improving health and child welfare (Strasburger, Jordan, \& Donnerstein, 2012). The internet and technology have advanced rapidly in the era of the 21 st century has created a non-formal learning environment. The data has shown that children ages 8-18 years spending more than 7.5 hours per day a week using media in school (Victoria J. Rideout, Foehr, \& Roberts, 2010). The use of screen media in communication has eliminated not only a direct communication, but also in personal activities (Giedd, 2012). The results of polling displayed the children have been exposed to technology, and they had used it since the age of 5 years. Its modern lifestyle has created psychology and physic discordance where humans and natural world. Reduction in contact with the natural world, means extinction of (ecological) experience. If this prompt is allowed to continue, it will negatively affect communication skills. Play and move as children please in their environment will refine their development naturally (Wang, Zhang, \& Baillargeon, 2016). The transfer of playing and moving from one place to another makes children understand each other's differences. This is very important as a foundation for developing their social skills.

One among factors contributing to children social skills is parenting style. Parenting style is quite significant to the development of their social skills (Saltali \& Arslan, 2012). These parenting styles contribute with parents' attitudes towards their children. That parents who actively participate in the children's education process, tend to make sure the training to have a higher quality, and the result of the training could be more permanent. The parents who have basic knowledge and skills taking roles in children's education revealed that their children are more successful in their education. The children will think that their mothers represent the world, and that each person in the world behave and act the same as their parents. Therefore, the parenting 
style is generally influenced by cultural features as shown (Riany, Cuskelly, \& Meredith, 2016). Children's behavior in early child will be shape the parenting styles impact on children behavior.

In terms of children's needs, it is important to build close relationships with parents so that they can display consistent behavior in the community to socialize with enthusiasm, independence and extroverted humans. This is also called a one-to-one situation related to childcare. It is common for parents and kindergarten teachers to rarely invite students to do outside activities on the grounds for the attention of strangers and lack of supervision from adults or teachers. A preliminary survey conducted by researchers showed that $91 \%$ of parents forgive their children for playing outside with safety, $85 \%$ stated that children do not do outside activities because they are still too small and fragile, and $60 \%$ found that parents do not allow them to play outside because of safety. This condition is similar to conditions in a kindergarten in South Jakarta. It is normal for parents and teachers to restrict children from playing outside for several reasons such as safety, worry about falling and getting hurt, children's clothes will get dirty and other reasons to support children's safety. The reason that parents agree with orders, and believe that this is not wrong is to protect their children. However, if this condition is left to remain, it will have an impact on children's social skills.

In addition, the style of raising children from parents is very important for healthy growth and for the child's existence able to develop positive personality structures. A positive parenting style contributes to the child becoming an individual who helps both himself and the community. Children will begin to shape their personalities and social behavior by building identification with the closest models Kol, 2016). Based on previous research problems, it is important to prove it through research that seeks a relationship between outdoor play with parenting styles in children's social abilities.

\section{THEORITICAL STUDY}

Childhood period is viewed as a moment of a playing time, having fun, and without coercion. Children who outdoor activity are physic beneficial, especially in developing their motoric skills (Fjørtoft \& Sageie, 2000). The free play in outdoor on children can offer physical health benefits, enhancing problem solve skills, building social interaction and emotional development. Some research has showed significantly the benefits of interact by environment are for emotional and physical health, especially through pathways that intertwined natural green spaces with higher levels of social cohesion and sense of community. The teachers in kindergarten carry out their obligations in assisting the growth and development of children as much as possible through stimulation with respect to develop all aspects of children's growth include motoric, and social aspects through playing activities that can be done outdoors. In fact, there is growth concern that children lose their willing on engage in environment world than spent doesn't enough outdoors activity, although there are many known benefits to children's health (Louv, 2008). Changes in society today has affected the children's play experiences in their childhood. The time to play outdoors is diminishing, contributing to a more sedentary lifestyle, cutting off from the natural world (Bento \& Dias, 2017). The uneasiness faced by the kindergarten teachers.

Are reluctant as they do not let the children to play outdoors for several reasonable aims, in attempt to avoid the children from bad people, accidents, and due to the limited green land availability. Research shown that measures the scale of relationship playing outdoors using The Attitudes toward Outdoor Play (ATOP)-fear show that the ATOP-fear scale is critical, negative related to nature, involved ride a bicycle, climb a tree, explore by Interest, this 
is negative related to have video games, even though this relationship is only slightly consequential. The ATOP-fear scale score was higher among children who reported that their parents did not support their outdoor play in nature, yet this association did not reach statistical significance. Additionally, the children in urban environments are less accessible, and lack of appropriateness in terms of having natural areas to play (Lindsey, Maraj, \& Kuan, 2001). This statement can be interpreted that the children find it difficult to get access to the natural outdoor play, as happens in all major cities in the world, that the natural areas has been covered by high-rise buildings, forced the children not to have proper spaces to play outdoors. Outdoor space is defined as an area with open space dominated by grass and trees. This definition does not include areas which are dominated by playground equipment nor recreation facilities where its use is controlled, but probably the areas with large portions of both (e.g., city parks may include abandoned fields, or tennis courts) (Beyer et al., 2015). Outdoor activities (e.g., playing, moving around) are very essential for the lives of children, allowing them to experience both natural and synthetic elements in their environment will result the development of their cognitive, physical and social skills. Azlina \& S., (2012) also claim that the children who play in nature have more positive feelings about each other. Special features and stimuli from the outside environment offer different play opportunities that can hardly be imitated indoors because they are still natural. The outdoor space could explained as an outside activity and changing environment, that is to move freely, rough crowded, that is associate the real as pure things. When outside activity, the kids take value from exposure to light, pure things and fresh air, as give bone growth, health, becomes stronger, supports gross motor development (Bento \& Dias, 2017).

\subsection{Outdoor Activities}

Playing outdoor is one of the things that characterizes childhood, giving children the chance to explore, discover, practice, change, make, ask questions, and learn about the world around them. The children's basic needs such as freedom, adventure, taking risks, experimentation, and just being children are supported by the outside environment. There are two common misconceptions about outdoor play: 1) outdoor play is the time for children only when they want to exert their excess energy, and 2) a playground is just a good environment for children to increase rough motor skills. Children learn best when all their senses are involved. They are drawn in direct exploration of the world around them. Interacting with the natural world instils them appreciation for the natural things in the environment and teach them to respect for nature. Thus, it can be interpreted that playing outside performs outdoor play activities which are crowded and has direct contact with natural objects, free to move, indeed provides benefits for the children's development and growth.

That abundant prove showing gain of outdoor activity are very broad. An important reason for playing outside for children in their early childhood is the number of developmental tasks that must be achieved by them, to name a few; exploration, taking risks, developing their fine and axial motor, along with maximal absorption of basic knowledge which learned effectively through playing outside and the increasingly unpredictable direction of academic development (Johnson \& Christie, 2009). During outside activity kids, are further more attractive than when they are inside room. These case could them to train gross motor doing activities, such as run, climb, swing, jump, and ride a bicycle. By playing outdoors actively while implementing these activities, they will instinctively build fine motor skills and cardiovascular endurance (Kozina et al., 2016). 
Early childhood education now requires children to master cognitive abilities yet the system is not carried out with activities which supports children's health, or the activities are only performed indoors. It explains why playing outdoor is deeply pivotal for their healthy development. Public health is improved by fresh breath, that is guarantee they can refresh respiratory infections, to defend virus, and advance a body health system. Moreover, the increase of social skills is promote by outdoor play. Kids become patient waiting their turn to descend slides, work with others to build sand castles, or play some organized games.

\subsection{1.2 Parenting Style}

Parenting style as a style that parents do in fulfilling child's rights starting from an early age even when the child still in the womb. The nurture and childcare must be give a reinforcement, in conduct with rules of family and communal life (Webster-Stratton, Reid, \& Hammond, 2001). that the parents need to be trained in parenting. Parenting styles is also influenced by culture (Riany, Meredith, \& Cuskelly, 2017). It leads the parents to take care their children, according to their understanding of their own cultures. The incorporation of cultures in parenting has positive patterns, and is a reinforcement for parents in carrying out nurturing and caring for children. There are three types of parenting styles applied by parents. They are called permissive, authoritative and democratic. Each parenting styles has advantages and disadvantages in the development and growth of children.

\subsection{Social Skills}

Social skills are believed to encourage good manners, school achievement, and child well-being. Good social skills are reasonably paramount for successful. Good social skills allow what we will say, make any decision, and know what should to do in unexpected condition. The peoples who have good social skills increase their personality, academic achievement, social activity, family engaging and embraced in extracurricular. Good behaviors are also pertained to the school environment quality and school security as well. Social skills as cognitive functions. It further covers to verbal and nonverbal functions and behaviors performed by individuals are intertwined as interacting with others, including verbal or nonverbal communication as pointed out by Coleman \& Lindsay, (1992).

The outdoor environment suggests attractive atmosphere for kids, and for older ages shown various factors of their personalities, that usually do not appear if their inside room. Based on the research result of Maynard \& Waters, (2007) we realize outside activity could high increase knowledge of kids, facilitating more education interventions of adults.

Likewise, less conflict occurs while playing outside and children tend to work more together. Space characteristics (e.g., open and unpredictable) reached the shared goals among children, which leads to experiences of friendship among peers. During outdoor activity, the children may become teachers and students, sharing their knowledge and skills to complete different tasks or challenges. In this collaborative process, it is possible to develop empathy when they begin to understand the feelings and needs of others. An essential difference about socialization in the outside environment is that the opportunity to interact occurs progressively. It gives the children the possibility to choose moments to interact and connect with others, or play individually, without having to keep walking with each other since it happens so often indoor, closed and adjoining rooms. Interaction with adults also seems to be facilitated in the outdoor play area. At different times throughout the project, the adults realize that they feel more available to support children 
outside, where they can feel calm and relaxed. This statement shows that the outdoor environment is not only a healthy environment for the children.

As students, the children who have good social skills in school had able to take social choices than strengthen self-interpersonal interaction and boost several accomplishments at learning. Good behavior which are able to be controlled by child include: (1) secure school environment, (2). Children's ability to resilience in the face crises forward or other pressure life (3). Children who are needs attention to overcome aggressive and stress, (4). The child who take personal responsibility for promoting school safety. Conversely, the children who are deficient in social skills have been proven for: (1). feel the difficulties in engagement to others (2). generate extremely refused from others that lead become the highest rejection of their peers. The rejection from others causes to several react with school abuse, (3). The children signs appear of depression, aggression and anxiety, (4). Less academic achievement as an indirect consequence, (5). Expose a higher of involvement in the criminal justice system, later when they become adults. The results of observations conducted that the lack of social behavior interferes with learning, teaching, and that many young people have never learned behavior which is suitable for social settings (situations where they have to interact or deal with others). They probably never learn by parents, either due to lack of training by older people or other systems of values and behaviors. Causes they haven't a role model at home and the environment that promoted appropriate behavior, but most of them did not implement it.

\section{METHODS}

\subsection{Participant}

This research was conducted in August 2018-December 2018. The research location in DKI Jakarta Regional Kindergarten School where TK is homogeneous. The research method used is quantitative research. The study population was 125 parents.

\subsection{Instrument}

The measured variables are determined in advance namely outdoor play which is designed to measure the components of the construct variable, namely: (1) confidence in the benefits of playing in the open (2) fear related to playing outside (obstacles), and (3) orientation towards unstructured game. Next to the variable dimensions of social skills namely: (1). Cooperation (2) Assertion (3) Responsibility (4) Empathy (5) Engagement (6) Self-Control. The aim is to calculate the total score scale from the three subscales above to measure the main aspects of children's attitudes towards playing in the open.

Social skills are defined as learned behaviors that encourage positive interactions and prevent negative interactions. Subdomains included in the Social Skills scale are: Communication, Cooperation, Assertiveness, Responsibility, Empathy, Engagement, and Self Control. Behavior standard scores are changed to a standard score of 100 and a standard deviation of 15 , according to the test norms. 


\subsection{Research design}

The research method is a descriptive study using the relational screening model which is a kind of screening model is a research model that aims to determine the existence or level of covariance between two and more variables.

\subsection{Procedure}

Parents are asked to fill out an assessment scale form to evaluate both social skills and problem behavior to evaluate both Social Skills and My Behavior Problems. In this measure, parents are asked to indicate how often the child displayed a variety of different behaviors during the last 2 months (never, rarely, often, almost always)

\subsection{Data Analysis}

Statistical analysis used Descriptive statistics were calculated for scale items. Relationships between variables were investigated using polychoric correlations which estimate correlations between underlying normally distributed latent variables, because items represent the category of streaks of the underlying continuous variables.

Factor analysis, using tilt rotation to allow correlation between factors, is used to examine the factor structure of items in the proposed scale. Hierarchies factor analysis is used to determine the measured items of an underlying construct. The correlation between scores based on factors and the average score of the analysis to determine the best methodology for assessment. Reliability uses ordinal alpha statistics based on polychoric correlations.

In addition, for each item the researcher calculated Cronbach's alpha if the item was deleted, itemscale correlation, and the proportion of respondents missed the item. Validity analysis was conducted to see the relationship between each scale and size of outdoor activities, sedentary activities, and support of parents to play outdoors.

\section{RESULT AND DISCUSSION}

\subsection{Result}

The Description of the Data. The following data obtained after using a questionnaire, then was made in the table below:

Table 1 The Description of the Data outdoor activity

\begin{tabular}{|c|c|c|c|c|}
\hline Statements & $\begin{array}{c}\text { Hard } \\
\text { disagree }\end{array}$ & Disagree & Agree & $\begin{array}{l}\text { Hard } \\
\text { Agree }\end{array}$ \\
\hline $\begin{array}{l}\text { Outdoor activity assists children to think } \\
\text { clearly. }\end{array}$ & $11(3 \%)$ & $17(5 \%)$ & $158(44 \%)$ & $174(48 \%)$ \\
\hline $\begin{array}{l}\text { Children feel scared of wild animals or bugs } \\
\text { outdoors. }\end{array}$ & $83(23 \%)$ & $151(42 \%)$ & $99(27 \%)$ & $26(7 \%)$ \\
\hline Children feel free while playing outdoors. & $11(3 \%)$ & $17(5 \%)$ & $158(44 \%)$ & $174(48 \%)$ \\
\hline $\begin{array}{l}\text { Playing outdoor in the nature promotes chil- } \\
\text { dren become healthier. }\end{array}$ & $6(2 \%)$ & $16(4 \%)$ & $170(47 \%)$ & $167(46 \%)$ \\
\hline $\begin{array}{l}\text { Children are afraid of being hurt playing out- } \\
\text { doors. }\end{array}$ & $108(30 \%)$ & $166(46 \%)$ & $67(19 \%)$ & $19(5 \%)$ \\
\hline
\end{tabular}




\begin{tabular}{lllll}
\hline $\begin{array}{l}\text { Children do not like playing outdoors as they } \\
\text { uncomfortable of their playmates. }\end{array}$ & $73(20 \%)$ & $122(34 \%)$ & $111(31 \%)$ & $51(14 \%$ \\
$\begin{array}{l}\text { Children are into exploring new games out- } \\
\text { doors. }\end{array}$ & $11(3 \%)$ & $36(10 \%)$ & $170(47 \%)$ & $143(40 \%)$ \\
$\begin{array}{l}\text { When a child is angry, playing outdoors } \\
\text { calm him down. }\end{array}$ & $21(6 \%)$ & $67(19 \%)$ & $166(46 \%)$ & $105(29 \%)$ \\
$\begin{array}{l}\text { Children do not like playing outdoors if } \\
\text { strangers around. }\end{array}$ & $33(26 \%)$ & $153(43 \%)$ & $85(23 \%)$ & $25(7 \%)$ \\
$\begin{array}{l}\text { Children love to try toys and games when } \\
\text { they are outdoors. }\end{array}$ & $13(4 \%)$ & $(11 \%) 193$ & $40(54 \%)$ & $114(31 \%)$ \\
$\begin{array}{l}\text { Children are afraid to fall while playing out- } \\
\text { doors. } \\
\text { Children are afraid of getting lost. }\end{array}$ & $125(35 \%)$ & $125(35 \%)$ & $97(27 \%)$ & $44(12 \%)$ \\
\hline
\end{tabular}

Based on the data about children's attitudes towards outdoor play activities can be described as follows: Table 1 show the frequency of responses each indicator. Child are very responsive that outdoor activity has a high value for personality. Were mostly believe $(48 \%)$ in the benefits of playing outdoors, help them to think more clearly, they feel free when playing outdoors (48\%), they like to explore new toys and games outside the environment (40\%) playing outside the room makes angry children become calmer (29\%), trying to play and move more when being outdoors (31\%). Data also shows that there are fears of wild animals or insects outdoors (7\%), afraid of being injured while playing outdoors $(5 \%)$, they are not playing outside because they are not comfortable with playmates (14\%), they also dislike playing outside because there are foreigners $(7 \%)$, afraid to fall while playing outdoors (12\%) and afraid to get lost $(46 \%)$.

\begin{tabular}{|c|c|c|c|c|c|c|c|c|c|c|c|c|}
\hline Think clearly & 1 & 0,3 & 0,41 & 0,5 & 0,31 & 0,01 & 0,01 & $-0,05$ & 0 & 0,01 & $-0,1$ & $-0,06$ \\
\hline Scared of Bugs & 0,3 & 1 & 0,45 & 0,46 & 0,41 & 0 & 0 & $-0,12$ & 0,12 & $-0,09$ & 0,08 & $-0,01$ \\
\hline Free & 0,44 & 0,45 & 1 & 0,44 & 0,46 & $-0,01$ & $-0,09$ & $-0,14$ & $-0,04$ & $-0,11$ & 0,08 & $-0,01$ \\
\hline Healthy & 0,5 & 0,46 & 0,4 & 1 & 0,52 & $-0,1$ & $-0,03$ & $-0,26$ & $-0,16$ & $-0,06$ & $-0,08$ & $-0,01$ \\
\hline Hurt & 0,36 & 0,41 & 0,44 & 0,51 & 1 & $-0,16$ & $-0,02$ & $-0,16$ & $-0,05$ & $-0,13$ & $-0,15$ & $-0,14$ \\
\hline Uncomfortable & 0,01 & 0 & $-0,01$ & $-0,1$ & $-0,14$ & 1 & 0,34 & 0,26 & 0,24 & 0,3 & 0,3 & 0,42 \\
\hline Exploring & 0,01 & 0 & $-0,06$ & $-0,02$ & $-0,02$ & 0,35 & 1 & 0,32 & 0,25 & 0,27 & 0,44 & 0,34 \\
\hline Calm & 0,06 & $-0,12$ & $-0,14$ & $-0,24$ & $-0,16$ & 0,24 & 0,33 & 1 & 0,3 & 0,25 & 0,33 & 0,42 \\
\hline Strangers & 0 & 0,11 & $-0,04$ & $-0,12$ & $-0,22$ & 0,25 & 0,23 & 0,3 & 1 & 0,31 & 0,32 & 0,45 \\
\hline Playing games & 0,02 & $-0,03$ & $-0,11$ & $-0,04$ & $-0,11$ & 0,3 & 0,23 & 0,22 & 0,36 & 1 & 0,32 & 0,33 \\
\hline Fall & $-0,01$ & 0,07 & $-0,05$ & $-0,03$ & $-0,13$ & 0,3 & 0,41 & 0,32 & 0,34 & 0,34 & 1 & 0,43 \\
\hline Lost & $-0,04$ & $-0,01$ & $-0,69$ & $-0,01$ & $-0,14$ & 0,43 & 0,32 & 0,4 & 0,43 & 0,31 & 0,41 & 1 \\
\hline & 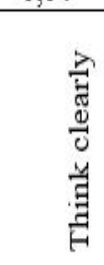 & 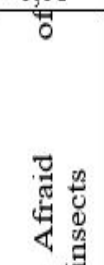 & 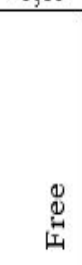 & 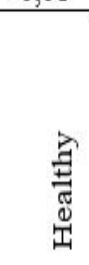 & 坣 & $\begin{array}{l}0 \\
0 \\
0 \\
\tilde{0} \\
0 \\
0 \\
0 \\
0 \\
0 \\
5\end{array}$ & 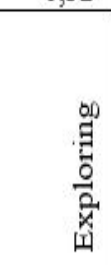 & 見 & 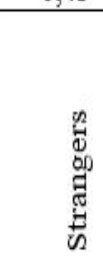 & 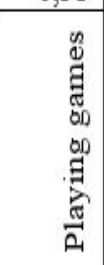 & $\begin{array}{l}\overline{\text { ज्ञ }} \\
\end{array}$ & 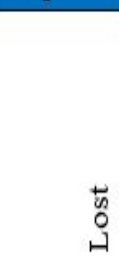 \\
\hline
\end{tabular}

Figure 1. Psychometric Analysis

Figure 1 shown the correlation of indicators in the scale. There are two groups of correlation plots. The first group shows concern about playing outdoors, or in the natural world, that the children face fear of wild animals or bugs outdoors, fear of being injure if playing outdoors, not playing outside because they are uncomfortable with playmates, do not enjoy outdoor activity because there are strangers, afraid to fall while playing outdoors and fear getting lost. The second group illustrates a positive correlation between the benefits of nature such as helping to think more clearly, feeling free when playing outdoors, likes to explore new toys outside the environment, making calm, trying toys and games while outdoors. The highest correlation is observed between 
the fear of strangers $(\mathrm{r}=0.45)$, fell $(\mathrm{r}=.043)$, uncomfortable $(\mathrm{r}=0.42)$, calm $(\mathrm{r}=.42)$, lost $(\mathrm{r}=$ $0.41)$, explored new games $(\mathrm{r}=0.34)$, think clearly $(\mathrm{r}=.0 .06)$, and found a negative correlation on the scale of injury, illness, freedom, fear of insects which is $(r=0.01)$ and there is no sharp negative correlation between each measure of fear and benefits.
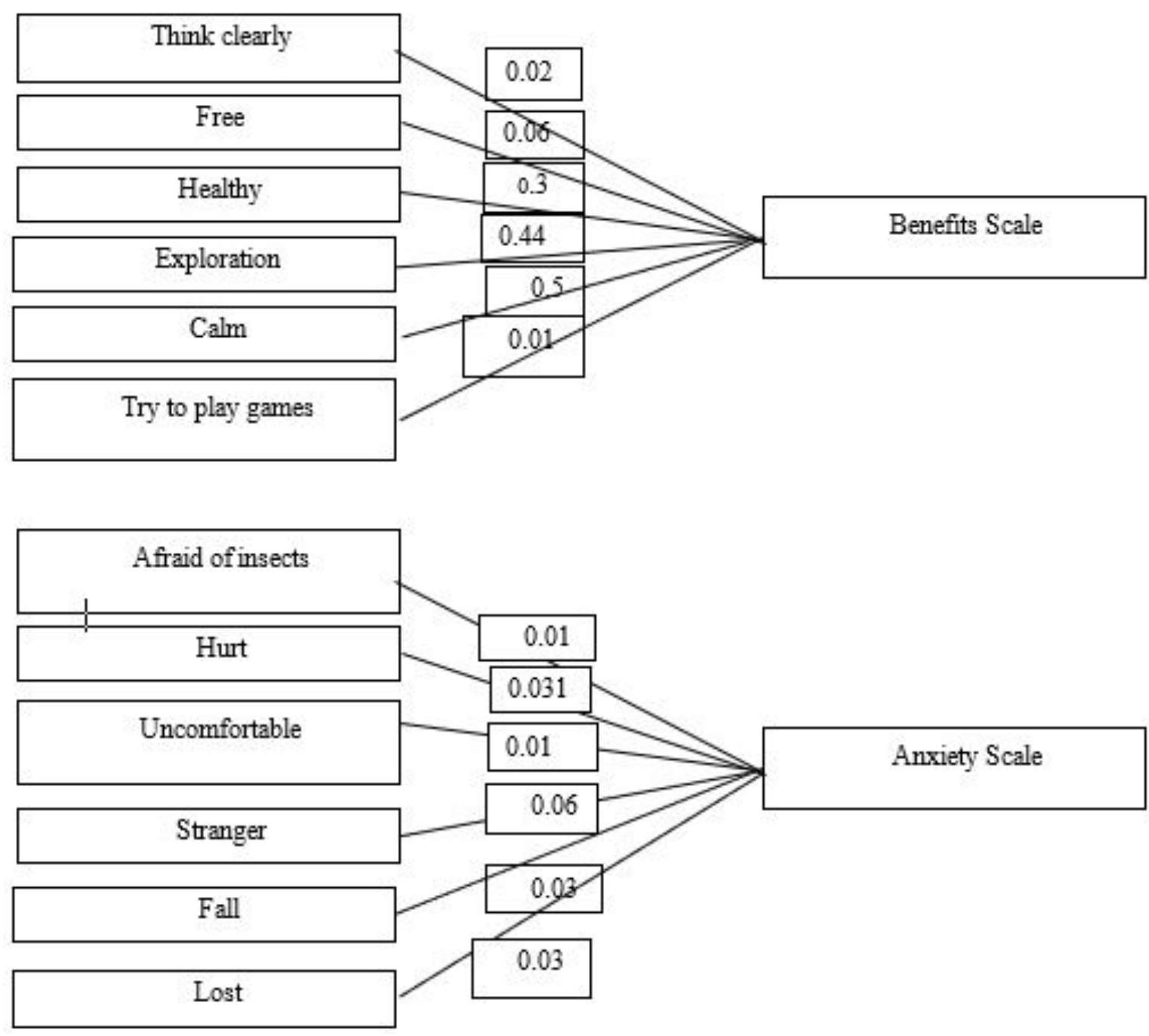

Figure 2. The Correlation Between Two Scales of Outdoor Play Attitude

This study uses a test of children's social skills, 23 items were finding out in a 3-point Likert-type scale, divided into three dimensions: civility and altruism, resources and self-control in social situations, and assertiveness with confronting. But the researchers determined only 7 items to be tested in the research sample. First- dimensions, politeness and altruism which involved abilities such as: The children behave politely, they convey thank you when praised, they say sorry, help their friends, and express positive feelings (smile, laugh, be happy).

Table 2. The Pearson Product Moment Correlation

\begin{tabular}{llll}
\hline No & Category & Number of Participant & Percentage \\
\hline 1 & Authoritative & 25 & $20.6 \%$ \\
2 & Permisive & 50 & $50.1 \%$ \\
3 & Democratic & 50 & $50.1 \%$ \\
\hline
\end{tabular}


Findings of Table 2 The Pearson product moment correlation is a result from changes in parental attitudes to children's social abilities. Positive correlation is attained in parenting democratic parents, and sub-dimensions of social skills rating scale reached- interpersonal skills, emotional management, and adaptation to change, ability to express verbally, self-control, listening skills. These results indicate that parenting democracy expands children's social skills. Despite of a correlation in a positive result in the sub-dimension of completing task skills, it is found that significant differences exist. In authoritative parents' side, it is found that there is a negative correlation in interpersonal skills, emotional management and adaptation to change, ability to express verbally, self-control, listening skills. These results indicate that as parents, they more actively protect the children, or their attitudes to their children was exaggerating which dwindle the children's social skills. In sub-dimensions of anger management and adaptation to skills change, lies a significant difference between the authoritative and permissive parenting style with children's social abilities, although weak negative correlations appear to be different significant.

\subsection{Discussion}

Both interpretable, valid scales emerge these studies were the scale of attitudes towards the gains of outdoor play $(\alpha=64)$ and attitudes towards the outdoor playground $(\alpha=64)$. The benefit scale includes the idea of playing in the open environment where it is beneficial to health, as well as to get the participants' understanding of the benefits of playing outdoor. The anxiety scale includes five statements which include concerns about outdoor play, including one item (strangers, and getting lost) that shows children's fear as one of a reason for playing outdoors. The purpose of this study is to find a connection between outdoor play and parenting style for these early childhood social abilities.

It seems child's perceptions of benefits and scary were of their understanding that the more complex outdoor play environment available, they see it as an opportunity to play outdoors. The findings in this study are purposeful and spontaneous, given the recognition that fear of playing outdoors cannot be understood as completely negative emotions, and is not always a boundary to perceive the benefits of playing in natural or outdoor environment, because somehow, these fears can be interpreted to have important benefits that is, self-care and caution against any danger that may arise when children play outdoors. Norðdahl \& Einarsdóttir, (2015) show that children want to challenge themselves also to be safe, explore things, connect with others, find or make nests and enjoy beautiful things outdoors. Children really appreciate the natural environment and like diversity in play equipment.

The ability to express verbally, self-control, listening skills, these results indicate that parenting democratic parenting increased, the social skills of children also increased. In the sub-dimension of the skill to complete the task even though there is a correlation in a positive way, it was found that there were significant differences. Authoritative parenting style found negative correlations seen in interpersonal skills, emotional management and adaptation to change, the ability to express verbally, self-control, listening skills, these results indicate that as parents more actively protect children or parental attitudes towards children who are overly, children's social skills are reduced. This concludes the results of research that states that psychologically parents who control the psychology of children in care will provide psychological experience in psychological development such as fear, guilt, negative behavior and tend to control others (Kemple, Oh, Kenney, \& Smith-Bonahue, 2016).

Furthermore, parents with parental control highly control their child's psychological impact on the low academic achievement of children (Pinquart, 2016). In the sub-dimension anger 
management and adaptation to skills changes, although there is a correlation in a negative way, a significant difference is found between parental authoritarian parenting and parents who implement permissive parenting with social abilities of children, although weak negative correlations are seen to exist significant difference.Two scales that can be interpreted and valid emerged from the research conducted, namely the scale of attitudes toward the benefits of playing outdoors (alpha $=64)$ and attitudes towards the scale of concern playing outside (alpha $=64)$. The benefits scale includes the idea of playing outdoors that is beneficial to health, as well as an understanding of the benefits of playing. The worries scale includes five statements that include the anxiety of playing outdoors, including one item (strangers, and being lost) which shows the children's fear of the reason for playing outdoors. The purpose of this study is to find an association between play outside the room and care for social abilities of these early childhood. It seems that children's perceptions about the benefits and fears are part of understanding more complex outdoor play environments as opportunities for outdoor play.

The findings in this study are very meaningful and intuitive, given the recognition that fear outdoor play cannot be understood as a completely negative emotion, and it is not always an obstacle to recognize the benefits of outdoor or natural play, because fear can be interpreted to have important benefits (Louv, 2008) namely, self-preservation and caution towards all the dangers that may arise when children play outdoors. Caution is needed given the significant health benefits of outdoor play for children (Boxberger \& Reimers, 2019). Outdoor play provides important skills development and health benefits for children (Wilkie, Standage, Gillison, Cumming, \& Katzmarzyk, 2018). Playing outdoors gives children the opportunity to perform executive functions (Moriguchi, Zelazo, \& Chevalier, 2016). Playing outdoors is preferred by children rather than watching videos and improving social skills in early childhood (Hinkley, Brown, Carson, \& Teychenne, 2018). Larson et al., (2019) show that contemporary children spend less time outside than their predecessors. The report also highlights the widespread use of electronic media in the lives of young people. More and more evidence is highlighting the negative effect of increasing screen time on outdoor time and on connections to nature. The attitude scale developed is a reliable and valid instrument for measuring attitudes toward outdoor play that can mediate physical activity in early childhood outside the room when in contact with nature. The attitude scale developed can be a useful tool for evaluating the impact of programs that will be carried out, such as environmental education programs, improving children's attitudes and behaviors towards the benefits of braininess outdoors and reducing children's concerns.

In addition, the scale can predict more optimal results between parenting patterns including the involvement of children in outdoor activities. Perhaps the most interesting finding from this study is the lack of a strong negative correlation between the benefit-scale scale and the scale of concern. Playing outdoors can be a therapy for children when interacting with nature outside the room, this is in line with the results of literature studies on the therapeutic landscape must describe the relationship between outdoor play and parenting towards children's social skills. This can be understood exploring children's understanding of the nature of the structure of play in the outdoor space in relation to their involvement in outdoor play. Parents play an important role in modeling healthy behaviors to their children. The relationship between physical activity of parents and children and screen time behavior across certain domains, including the effects of moderation by parents and the sex of the child. Children like to spend more time playing outdoors when they have parents who also spend more time in outdoor activities (Schoeppe et al., 2017). Another advantage of outdoor play for children is connecting to nature and spending time outdoors as 
children have been indicated as predictors of environmentally responsible behavior (Mullenbach, Andrejewski, \& Mowen, 2019).

Parents need to get reinforcement to apply parenting to children (Webster-Stratton et al., 2001). Thus, parents are expected to attend childcare training. Agreeing with this is the benefit of parents who participate in parenting program training to have experience and positive benefits when with their children (Moreland \& McRae-Clark, 2018). Furthermore, parental care that is not good to be one source of causes of children become stressed in achieving social competence as an adult (Cui, Janhonen-Abruquah, Darling, Carlos Chavez, \& Palojoki, 2019). Parents need not interfere in children's activities (Waters \& Rekers, 2019). It is hoped that parents can give children the opportunity to play outdoors in the hope that children's growth and development will be maximized through outdoor play activities.

\section{CONCLUSION}

\subsection{Conclusion}

Based on the results of research conducted, the researchers conclude as follows: The results of the study conducted are the scale of attitudes towards the benefits of playing outdoors and the attitude to the scale of concern playing outdoors, the benefits scale includes the idea of playing outdoors that is beneficial to health, as well as an understanding of -the benefits of play, the anxiety scale includes five statements that include the worry of playing outdoors, including one item (strangers, and being lost) that shows children's fears about the reason for playing outdoors. In the study found a relationship between play outdoors and parenting towards these early childhood social skills, children's perceptions about the benefits and fears are part of understanding more complex outdoor play environments as opportunities to play outdoors.

The results showed parenting democracy parenting improved children's social skills. In the subdimension of the task completion skills although there was a correlation in a positive way, it was found that there were significant differences. Authoritative parenting style found negative correlations seen in interpersonal skills, emotional management and adaptation to change, the ability to express verbally, self-control, listening skills, these results indicate that as parents more actively protect children or parental attitudes towards children who are overly, children's social skills are reduced.

In the subdimension of anger management and adaptation to skills changes, although there is a correlation in a negative way, a significant difference is found between parental authoritarian parenting and parents who implement permissive parenting with social abilities of children, although weak negative correlations are seen to exist significant difference. The findings in this study are very meaningful and intuitive, given the recognition that the fear of playing outdoors cannot be understood as a completely negative emotion, and it is not always a barrier to recognizing the benefits of outdoor or natural play, because of the fear can be interpreted to have benefits, namely, self-care and caution against all the dangers that may arise when children play outdoors. 


\subsection{Suggestion}

Suggestion In this study the researchers suggested several things including: Parenting patterns will determine the courage of children to play outside the room. Parents should not be too protective of children to play outside the room. Playing outdoors can be done as an emotional therapy for children, but parents should provide assistance to children so that children get the attitude of benefits higher than the scale of concern. Playing outside the room provides benefits including the scale of the attitude of benefit and concern, but anxiety is precisely a means for children to be more careful and take care of themselves. Researchers only examined the relationship between outdoor play, parenting and social skills of children. Researchers can then develop to look for relationships with other aspects of ability in early childhood.

\section{REFERENCES}

Azlina, W., \& S., Z. A. (2012). A Pilot Study: The Impact of Outdoor Play Spaces on Kindergarten Children. Procedia - Social and Behavioral Sciences, 38(December 2010), 275-283. https://doi.org/10.1016/j.sbspro.2012.03.349

Bento, G., \& Dias, G. (2017). The importance of outdoor play for young children's healthy development. Porto Biomedical Journal, 2(5), 157-160. https://doi.org/10.1016/j.pbj.2017.03.003

Beyer, K., Bizub, J., Szabo, A., Heller, B., Kistner, A., Shawgo, E., \& Zetts, C. (2015). Development and validation of the attitudes toward outdoor play scales for children. Social Science and Medicine, 133, 253-260. https://doi.org/10.1016/j.socscimed.2014.10.033

Boxberger, K., \& Reimers, A. K. (2019). Parental correlates of outdoor play in boys and girls aged 0 to 12-A systematic review. International Journal of Environmental Research and Public Health, 16(2). https://doi.org/10.3390/ijerph16020190

Coleman, W. L., \& Lindsay, R. L. (1992). Interpersonal disabilities: Social skill deficits in older children and adolescents: Their description, assessment, and management. Pediatric Clinics of North America, 39(3), 551-567. https://doi.org/10.1016/S0031-3955(16)38344-4

Cui, M., Janhonen-Abruquah, H., Darling, C. A., Carlos Chavez, F. L., \& Palojoki, P. (2019). Helicopter Parenting and Young Adults' Well-Being: A Comparison Between United States and Finland. Cross-Cultural Research, 53(4), 410-427. https://doi.org/10.1177/1069397118802253

Fjørtoft, I., \& Sageie, J. (2000). The natural environment as a playground for children. Landscape description and analyses of a natural playscape. Landscape and Urban Planning, 48(1-2), 83-97. https://doi.org/10.1016/S0169-2046(00)00045-1

Ghanbari-Azarneir, S., Anbari, S., Hosseini, S.-B., \& Yazdanfar, S.-A. (2015). Identification of Child-friendly Environments in Poor Neighborhoods. Procedia - Social and Behavioral Sciences, 201(February), 19-29. https://doi.org/10.1016/j.sbspro.2015.08.114

Giedd, J. N. (2012). The Digital Revolution and Adolescent Brain Evolution. Journal of Adolescent Health, 51(2), 101-105. https://doi.org/10.1016/j.jadohealth.2012.06.002

Hinkley, T., Brown, H., Carson, V., \& Teychenne, M. (2018). Cross sectional associations of screen time and outdoor play with social skills in preschool children. PLOS ONE, 13(4), 115. https://doi.org/10.1371

Johnson, J. E., \& Christie, J. F. (2009). Play and digital media. Computers in the Schools, 26(4), 284-289. https://doi.org/10.1080/07380560903360202

Junot, A., Paquet, Y., \& Martin-Krumm, C. (2017). Passion for outdoor activities and environmental behaviors: A look at emotions related to passionate activities. Journal of 
Environmental Psychology, 53, 177-184. https://doi.org/10.1016/j.jenvp.2017.07.011

Kemple, K. M., Oh, J. H., Kenney, E., \& Smith-Bonahue, T. (2016). The Power of Outdoor Play and Play in Natural Environments. Childhood Education, 92(6), 446-454. https://doi.org/10.1080/00094056.2016.1251793

Kol, S. (2016). The Effects of the Parenting Styles on Social Skills of Children Aged 5-6. Malaysian Online Journal of Educational Sciences, 4(2), 49-58.

Kozina, Z., Repko, O., Kozin, S., Kostyrko, A., Yermakova, T., \& Goncharenko, V. (2016). Motor skills formation technique in 6 to 7 -year-old children based on their psychological and physical features (Rock climbing as an example). Journal of Physical Education and Sport, 16(3), 866-874. https://doi.org/10.7752/jpes.2016.03137

Larson, L. R., Szczytko, R., Bowers, E. P., Stephens, L. E., Stevenson, K. T., \& Floyd, M. F. (2019). Outdoor Time, Screen Time, and Connection to Nature: Troubling Trends Among Rural Youth? Environment and Behavior, 51(8), 966-991. https://doi.org/10.1177/0013916518806686

Lindsey, G., Maraj, M., \& Kuan, S. C. (2001). Access, Equity, and Urban Greenways: An Exploratory Investigation. Professional Geographer, 53(3), 332-346. https://doi.org/10.1111/0033-0124.00288

Louv, R. (2008). Last child in the woods: Saving our children from nature-deficit disorder. Chapel Hill, NC: Algonquin Books.

Maynard, T., \& Waters, J. (2007). Learning in the outdoor environment: A missed opportunity? Early Years, 27(3), 255-265. https://doi.org/10.1080/09575140701594400

Moreland, A. D., \& McRae-Clark, A. (2018). Parenting outcomes of parenting interventions in integrated substance-use treatment programs: A systematic review. Journal of Substance Abuse Treatment, 89(August 2017), 52-59. https://doi.org/10.1016/j.jsat.2018.03.005

Moriguchi, Y., Zelazo, P. D., \& Chevalier, N. (2016). Development of Executive Function During Childhood. https://doi.org/10.3389/978-2-88919-800-9

Mullenbach, L. E., Andrejewski, R. G., \& Mowen, A. J. (2019). Connecting children to nature through residential outdoor environmental education. Environmental Education Research, 25(3), 365-374. https://doi.org/10.1080/13504622.2018.1458215

Norðdahl, K., \& Einarsdóttir, J. (2015). Children's views and preferences regarding their outdoor environment. Journal of Adventure Education and Outdoor Learning, 15(2), 152-167. https://doi.org/10.1080/14729679.2014.896746

Pinquart, M. (2016). Associations of Parenting Styles and Dimensions with Academic Achievement in Children and Adolescents: A Meta-analysis. Educational Psychology Review, 28(3), 475-493. https://doi.org/10.1007/s10648-015-9338-y

Riany, Y. E., Cuskelly, M., \& Meredith, P. (2016). Cultural Beliefs about Autism in Indonesia. International Journal of Disability, Development and Education, 63(6), 623-640. https://doi.org/10.1080/1034912X.2016.1142069

Riany, Y. E., Meredith, P., \& Cuskelly, M. (2017). Understanding the Influence of Traditional Cultural Values on Indonesian Parenting. Marriage and Family Review, 53(3), 207-226. https://doi.org/10.1080/01494929.2016.1157561

Saltali, N. D., \& Arslan, E. (2012). Parent's Attitudes as a Predictor of Preschoolers' Social Competence and Introverted Behavior. Elementary Education Online, 11(3), 729-737.

Schoeppe, S., Vandelanotte, C., Bere, E., Lien, N., Verloigne, M., Kovács, É., ... Van Lippevelde, W. (2017). The influence of parental modelling on children's physical activity and screen time: Does it differ by gender? European Journal of Public Health, 27(1), 152-157. 
https://doi.org/10.1093/eurpub/ckw182

Shi, Y. (2017). Explore Children's Outdoor Play Spaces of Community Areas in High-density Cities in China: Wuhan as an Example. Procedia Engineering, 198(September 2016), 654682. https://doi.org/10.1016/j.proeng.2017.07.118

Strasburger, V. C., Jordan, A. B., \& Donnerstein, E. (2012). Children, Adolescents, and the Media:. Health Effects. Pediatric Clinics of North America, 59(3), 533-587. https://doi.org/10.1016/j.pcl.2012.03.025

Victoria J. Rideout, Foehr, M. A. U. G., \& Roberts, D. F. (2010). GENERATION M2 Media in the Lives of 8- to 18-Year-Olds. In Theresa Boston (Ed.), Henry J. Kaiser Family Foundation. Boston: Henry J. Kaiser Family Foundation.

Wang, S. hua, Zhang, Y., \& Baillargeon, R. (2016). Young infants view physically possible support events as unexpected: New evidence for rule learning. Cognition, 157, 100-105. https://doi.org/10.1016/j.cognition.2016.08.021

Waters, J., \& Rekers, A. (2019). Young Children 's Outdoor Play-Based Learning. 1-7.

Webster-Stratton, C., Reid, J., \& Hammond, M. (2001). Social skills and problem-solving training for children with early-onset conduct problems: Who benefits? Journal of Child Psychology and Psychiatry and Allied Disciplines, 42(7), 943-952. Retrieved from http://ovidsp.ovid.com/ovidweb.cgi?T=JS\&PAGE=reference $\& D=$ emed5\&NEWS=N\&AN $=2001380196$

Wilkie, H. J., Standage, M., Gillison, F. B., Cumming, S. P., \& Katzmarzyk, P. T. (2018). The home electronic media environment and parental safety concerns: relationships with outdoor time after school and over the weekend among 9-11 year old children. BMC Public Health, 18(1), 456. https://doi.org/10.1186/s12889-018-5382-0

Zajenkowska, A., Jankowski, K. S., Lawrence, C., \& Zajenkowski, M. (2013). Personality and individual differences in responses to aggression triggering events among prisoners and nonprisoners. Personality and Individual Differences, 55(8), 947-951. https://doi.org/10.1016/j.paid.2013.07.467 